\title{
Nucleolipid Acid-Based Nanocarriers Restore Neuronal Lysosomal Acidification Defects
}

\author{
Mathias Brouillard ${ }^{1}$, Philippe Barthélémy ${ }^{1}$, Benjamin Dehay ${ }^{2 *}$, Sylvie Crauste-Manciet ${ }^{1,3}$ and \\ Valérie Desvergnes ${ }^{1 *}$
}

${ }^{1}$ University of Bordeaux, INSERM U1212, UMR CNRS 5320, Bordeaux, France, ${ }^{2}$ University of Bordeaux, CNRS, IMN, UMR 5293, Bordeaux, France, ${ }^{3}$ University Hospital, Bordeaux, France

\section{OPEN ACCESS}

Edited by:

Srivatsan Seergazhi Gopalan, Indian Institute of Science Education and Research, Pune, India

Reviewed by: Ashok Nuthanakanti, NYU Grossman School of Medicine, United States Ashwani Sharma, IISER Tirupati, India

*Correspondence: Benjamin Dehay benjamin.dehay@u-bordeaux.fr Valérie Desvergnes valerie.desvergnes@u-bordeaux.fr

Specialty section:

This article was submitted to Supramolecular Chemistry, a section of the journal Frontiers in Chemistry

Received: 05 July 2021 Accepted: 06 August 2021 Published: 20 August 2021

Citation: Brouillard $M$, Barthélémy $P$, Dehay $B$, Crauste-Manciet $S$ and Desvergnes $V$ (2021) Nucleolipid Acid-Based Nanocarriers Restore Neuronal Lysosomal Acidification Defects.

Front. Chem. 9:736554. doi: 10.3389/fchem.2021.736554
Increasing evidence suggests that lysosomal dysfunction has a pathogenic role in neurodegenerative diseases. In particular, an increase in lysosomal $\mathrm{pH}$ has been reported in different cellular models of Parkinson's disease. Thus, targeting lysosomes has emerged as a promising approach. More specifically, regulating its $\mathrm{pH}$ could play a central role against the neurodegeneration process. To date, only a few agents specifically targeting lysosomal $\mathrm{pH}$ are reported in the literature, partly due to the challenge of crossing the Blood-Brain-Barrier (BBB), preventing drug penetration into the central nervous system (CNS). To develop chronic treatments for neurodegenerative diseases, crossing the BBB is crucial. We report herein the conception and synthesis of an innovative DNA derivative-based nanocarrier. Nucleolipids, carrying a biocompatible organic acid as an active ingredient, were designed and synthesized as prodrugs. They were successfully incorporated into an oil-in-water nanoemulsion vehicle to cross biological membranes and then release effectively biocompatible acidic components to restore the functional lysosomal pH of neuronal cells. Biological assays on a genetic cell model of Parkinson's disease highlighted the non-toxicity of such nucleolipids after cellular uptake and their ability (at $\mathrm{c}=40 \mu \mathrm{M})$ to fully restore lysosomal acidity.

Keywords: nucleolipid, nanocarrier, oil-in-water nanoemulsion, lysosome, pH, acidification, neurodegenerative disease

\section{INTRODUCTION}

Lysosomes play a crucial role in many cellular processes. These membrane-bound acidic organelles present in the cytosol of all eukaryotic cells are particularly implicated in the autophagy-lysosomal pathway (ALP) (Luzio et al., 2007), (Yim and Mizushima, 2020). The ALP is the main mechanism for the degradation of intracellular material and, notably, long-lived proteins and old or damaged organelles. The degradation process requests a crucial acidic lysosomal $\mathrm{pH}$ (4.5-5.5), which optimizes the concerted action of more than 60 hydrolases (Settembre et al., 2013) and ensures fusion between lysosomes and autophagosomes (Kawai et al., 2007). The significant role of the lysosome $\mathrm{pH}$ has become evident in many pathologies such as lysosomal storage disorders (Marques and Saftig, 2019), immunological diseases, diabetes, cancer, and neurodegenerative diseases (Koh et al., 2019), (Colacurcio and Nixon, 2016), making the lysosome a promising therapeutic target (Hafner Česen et al., 2012), (Bonam et al., 2019), (Peng et al., 2019). In the specific case of neurodegenerative diseases, particularly in Parkinson's disease (Dehay et al., 2013), the toxic accumulation of misfolded proteins and subsequent neurodegeneration has been linked to 
lysosomal dysfunction (Dehay et al., 2010), (Lie and Nixon, 2019). Approaches to modulate lysosomal pH are scarce. Developing therapeutic nanosystems with acidic drug delivery to restore lysosomal acidification are of significant interest (Zeng et al., 2020). The main issue is to target neuronal lysosomes in neurodegenerative diseases to transport therapeutic agents to the central nervous system (CNS) and then pass through the BloodBrain-Barrier (BBB). The size of nanoobjects and their lipophilic nature are crucial to cross this natural protective membrane (Zhang et al., 2009), (Rathore et al., 2019), (Edelmann and Maegawa, 2020). Polymeric or lipid nanoparticles (NPs) were developed to exhibit specific characteristics allowing the uptake into CNS. Mainly, PLGA polyester nanoparticles (diameter $100 \mathrm{~nm}$ ) are used to target CNS (Cunha et al., 2021). This $\mathrm{pH}$ and enzyme-sensitive polymer releases lactic and glycolic acid residues in a mild acid aqueous environment and has been reported to decrease lysosomal $\mathrm{pH}$ efficiently (Bourdenx et al., 2016), (Zeng et al., 2019). To achieve CNS targeting by systemic injection and overcome the low diffusion power of PLGA NPs in the brain, the development of oil-in-water $(\mathrm{O} / \mathrm{W})$ nanoemulsions (NEs)-based formulation was recently reported (Prévot et al., 2018). Potential of NEs for drug delivery to the brain was recently reviewed (Karami et al., 2019), highlighting the essential properties of NEs to this goal for hydrophobic therapeutics agents entrapped inside oil droplets, i.e., cellular transport either by paracellular or transcellular routes, the colloidal dispersion protecting them from both chemical and enzymatic degradations. Considering these properties and their biocompatibility based on excipients, which may be selected as Generally Recognized As Safe (GRAS), allowing their administration in humans, NE represents an excellent nanosystem for drug delivery and sustained drug release.

Nevertheless, the low solubility of PLGA polymer in oil and its limited loading rate into resulting $\mathrm{NE}$ led us to design and synthesize a small low molecular weight molecule able to be efficiently loaded into NE. Nucleolipids (NLs) are small hybrid bioinspired molecules composed of a lipid covalently linked to a nucleic acid derivative, nucleobase, nucleoside, nucleotide, or oligonucleotide with a certain structural similarity to cell membranes (Gissot et al., 2008). It is widely accepted that NLs are efficient molecular carriers for the delivery of therapeutic ingredients (Simeone et al., 2011), (Benizri et al., 2018), (Zhou et al., 2020). Their ability to cross the BBB was also recently highlighted (Swastika et al., 2019), making them good candidates for our goal. Based on this outcome, it was first demonstrated that a NL appropriately functionalized could be loaded in an O/W NE and subsequently efficiently internalized within human neuronal cells and co-localized with targeted lysosomes (Cunha et al., 2020).

To go further, we report here the synthesis, the formulation, and the biological evaluation of original NLs designed as prodrugs and carrying an organic acid moiety as a potential lysosomal acidifying agent (Figure 1). Succinic acid was chosen on its excellent biocompatibility and its pKa range remarkably close to lactic and glycolic acids pKas. The free acid function was expected to provide rapid acidification. In contrast, the second acid function, protected as an ester at the $5^{\prime}$ position, will be released in a second time via enzymatic cleavage. Their formulation into $\mathrm{O} / \mathrm{W}$ NEs was performed to allow the plasma membrane crossing. The nature of the fatty chain at the $3^{\prime}$ position was modulated to study the effect of the lipid chain length on cytotoxicity and acidifying capacity. The encouraging results reported herein suggest that $\mathrm{O} / \mathrm{W}$ NEs loaded with acid NLs are efficient nanocarriers for drug delivery. Indeed, it has been shown that acidic NLs are easily transported to the lysosomes and rescue efficiently the impaired $\mathrm{pH}$.

\section{MATERIALS AND METHODS}

\section{Synthesis and Characterization of Acidic Nucleolipids 7-8 \\ General Methods}

${ }^{1} \mathrm{H}$ NMR and ${ }^{13} \mathrm{C}$ NMR were recorded on a Bruker Avance 300 $\left({ }^{1} \mathrm{H}: 300 \mathrm{MHz},{ }^{13} \mathrm{C}: 75.46 \mathrm{MHz}\right)$ spectrometer using residual

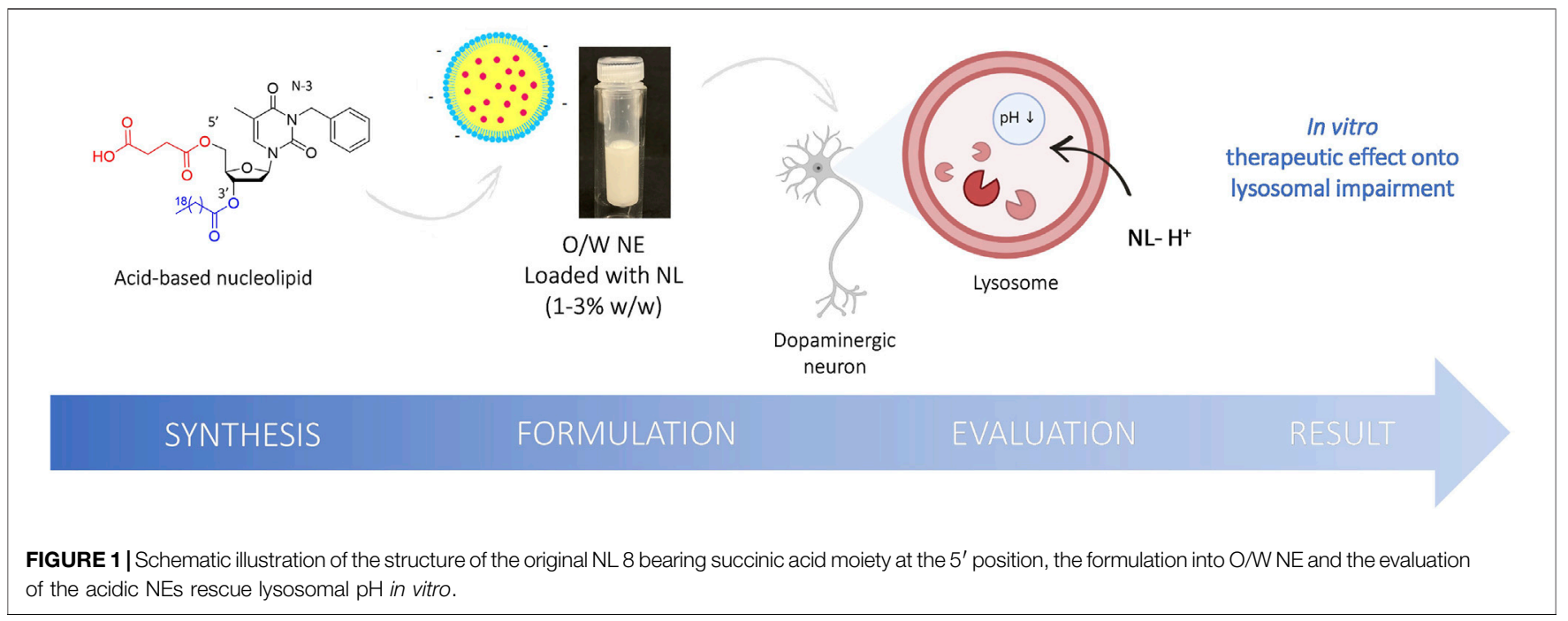


$\mathrm{CHCl}_{3}$ as an internal reference $(7.26 \mathrm{ppm})$ and at $293 \mathrm{~K}$ unless otherwise indicated. The chemical shifts $(\delta)$ and coupling constants $(J)$ are expressed in ppm and $\mathrm{Hz}$. The following abbreviations were used to explain the multiplicities: $s=$ singlet, $\mathrm{d}=$ doublet, $\mathrm{t}=$ triplet, $\mathrm{q}=$ quartet and $\mathrm{m}=$ multiplet. Fourier transform infrared (FT-IR) spectra were recorded on a PerkinElmer FT spectrometer Spectrum two (UATR two). For electrospray ionization (ESI) high-resolution mass spectrometry (HRMS) analyses, a Waters Micromass ZQ instrument equipped with an electrospray source was used in the positive and/or negative mode. Matrix-assisted laser desorption ionization time-of-flight (MALDI-TOF) mass spectrometric analyses were performed on a PerSeptive Biosystems Voyager-De Pro MALDI mass spectrometer in the linear mode using 3,4dihydroxybenzoic acid as the matrix. Analytical thin-layer chromatography was performed using silica gel 60 F254 precoated plates (Merck) with visualization by ultraviolet light, potassium permanganate, or sulfuric acid. Flash chromatography was performed on a silica gel $(0.043-0.063 \mathrm{~mm})$.

\section{Synthesis of Compound 1}

In a vial, to a solution of thymidine ( 1 eq., $1 \mathrm{~g}, 4.13 \mathrm{mmol}$ ) in anhydrous DMF $(10 \mathrm{ml})$ and under argon atmosphere, $\mathrm{NaH}$ ( 1 eq., $0.166 \mathrm{~g}$ ) was added before a microwave activation $\left(6 \mathrm{~min}, 40^{\circ} \mathrm{C}, 200 \mathrm{~W}\right)$. Then, benzyl bromide (1 eq., $\left.490 \mu \mathrm{L}\right)$ was added, and the reaction mixture was heated in a microwave $\left(60 \mathrm{~min}, 40^{\circ} \mathrm{C}, 200 \mathrm{~W}\right)$. DMF was then evaporated with toluene without any further treatment. The reaction was repeated three times, the crudes were collected and purified by flash chromatography over silica gel (DCM/ MeOH: 95/5) to afford the compound 1 as an expended solid (3.9 g, $95 \%)$.

$\mathrm{R}_{\mathrm{f}}=0.4$ (DCM/MeOH: 95/5). IR (ATR) vmax $\left(\mathrm{cm}^{-1}\right) 3410$, 2924, 2861, 1947, 1650, 1563, 1392, 1256, 1095, 655, 488. ${ }^{1} \mathrm{H}-$ NMR $\left(300 \mathrm{MHz}, \mathrm{CD}_{3} \mathrm{OD}\right) \delta(\mathrm{ppm}) 7.86(\mathrm{~d}, J=1.2 \mathrm{~Hz}, 1 \mathrm{H})$, $7.38-7.17(\mathrm{~m}, 5 \mathrm{H}), 6.31$ (appearing t, $J=6.9,13.5 \mathrm{~Hz}, 1 \mathrm{H}), 5.08$ (brs, $2 \mathrm{H}), 4.43-4.35(\mathrm{~m}, 1 \mathrm{H}), 3.94-3.87(\mathrm{~m}, 1 \mathrm{H}), 3.76$ (ddd, $J=$ 2.7, 11.4, 23.1 Hz, 2H), 2.32-2.13 (m, 2H), $1.91(\mathrm{~s}, 3 \mathrm{H}) .{ }^{13} \mathrm{C}-\mathrm{NMR}$ (75.5 MHz, CD $3 \mathrm{OD}) \delta(\mathrm{ppm}) 165.3,152.4,138.3,136.6,129.4$, 129.3, 128.4, 110.7, 88.9, 87.1, 72.1, 62.7, 45.3, 41.3, 13.2. HRMS (ESI): Calcd. for $\mathrm{C}_{17} \mathrm{H}_{20} \mathrm{~N}_{2} \mathrm{O}_{5}[\mathrm{M}+\mathrm{H}]^{+}$333.13722, found 333.14470 .

\section{Synthesis of Compound 2}

To a solution of compound 1 ( 1 eq., $3.18 \mathrm{~g}$, $9.53 \mathrm{mmol}$ ) into dry pyridine $(65 \mathrm{ml})$, were added under argon $t$-Butyldimethylsilyl chloride (1.2 eq., $1.73 \mathrm{~g}, 11.2 \mathrm{mmol}$ ) and the DMAP (0.1 eq., $116 \mathrm{mg}, \quad 0.953 \mathrm{mmol})$. The reaction mixture was stirred overnight at room temperature and then quenched with water $(30 \mathrm{ml})$. The aqueous phase was extracted three times with DCM $(3 \times 30 \mathrm{ml})$, and the combined organic phases were dried over $\mathrm{Na}_{2} \mathrm{SO}_{4}$ before concentration under reduced pressure. The crude product was purified by flash chromatography over silica gel (Pentane/EtOAc: 70/30) to afford compound 2 as an expended solid (1.78 g, $89 \%)$.

$\mathrm{R}_{\mathrm{f}}=0.3$ (Pentane/EtOAc: 70/30). ${ }^{1} \mathrm{H}-\mathrm{NMR}\left(300 \mathrm{MHz}, \mathrm{CDCl}_{3}\right)$ $\delta$ (ppm) 7.54-7.45 (m, 3H), 7.34-7.22 (m, 3H), 6.41 (dd, $J=5.7$,
$7.8 \mathrm{~Hz}, 1 \mathrm{H}), 5.17-5.10$ (brs, $2 \mathrm{H}), 4.50-4.42$ (m, 1H), 4.06-3.99 $(\mathrm{m}, 1 \mathrm{H}), 3.90(\mathrm{dd}, J=2.7,11.4 \mathrm{~Hz}, 1 \mathrm{H}), 3.82(\mathrm{dd}, J=2.7,11.4 \mathrm{~Hz}$, $1 \mathrm{H}), 2.38$ (ddd, $J=2.4,5.7,13.2 \mathrm{~Hz}, 1 \mathrm{H}), 2.16-2.04(\mathrm{~m}, 1 \mathrm{H}), 1.95$ $(\mathrm{s}, 3 \mathrm{H}), 0.93(\mathrm{~s}, 9 \mathrm{H}), 0.13(\mathrm{~s}, 3 \mathrm{H}), 0.12(\mathrm{~s}, 3 \mathrm{H}) .{ }^{13} \mathrm{C}-\mathrm{NMR}(75.5$ $\left.\mathrm{MHz}, \mathrm{CDCl}_{3}\right) \delta$ (ppm) 163.6, 151.1, 137.0, 133.7, 129.2, 128.5, 127.7, 110.3, 87.0, 85.7, 72.6, 63.6, 44.6, 41.4, 26.0, 18.5, 13.5, -5.3, -5.4. Analytical data are consistent with the literature (Cunha et al., 2020).

\section{Synthesis of Compound 3}

To a solution of compound 2 ( 1 eq., $0.718 \mathrm{~g}, 1.82 \mathrm{mmol}$ ) into dry DCM $(10 \mathrm{ml})$, was added under argon the palmitic acid ( 1.2 eq., $0.560 \mathrm{~g}, 2.18 \mathrm{mmol}$ ), the $\mathrm{EDC}$. $\mathrm{HCl}(1.2 \mathrm{eq} ., 0.419 \mathrm{~g}$, $2.18 \mathrm{mmol}$ ) and the DMAP (0.5 eq., $0.111 \mathrm{~g}, 0.90 \mathrm{mmol})$. The reaction mixture was stirred at room temperature for $48 \mathrm{~h}$ and then quenched with water $(10 \mathrm{ml})$. The aqueous phase was extracted three times with DCM $(3 \times 30 \mathrm{ml})$, and the combined organic phases were dried over $\mathrm{Na}_{2} \mathrm{SO}_{4}$ before concentration under reduced pressure. The crude product was purified by flash chromatography over silica gel (Pentane/EtOAc: 70/30) to provide compound 3 as a white foam (1.19 g, quantitative yield).

$\mathrm{R}_{\mathrm{f}}=0.9$ (Pentane/EtOAc: 70/30) ${ }^{1} \mathrm{H}-\mathrm{NMR}\left(300 \mathrm{MHz}, \mathrm{CDCl}_{3}\right)$ $\delta(\mathrm{ppm}) 7.54(\mathrm{~d}, J=1.2 \mathrm{~Hz}, 1 \mathrm{H}), 7.52-7.47(\mathrm{~m}, 2 \mathrm{H}), 7.35-7.22(\mathrm{~m}$, $3 \mathrm{H}), 6.42(\mathrm{dd}, J=5.1,9.3 \mathrm{~Hz}, 1 \mathrm{H}), 5.30-5.23(\mathrm{~m}, 1 \mathrm{H}), 5.19-5.09$ $(\mathrm{m}, 2 \mathrm{H}), 4.10-4.05(\mathrm{~m}, 1 \mathrm{H}), 3.98-3.86(\mathrm{~m}, 2 \mathrm{H}), 2.40(\mathrm{dd}, J=5.4$, $13.8 \mathrm{~Hz}, 1 \mathrm{H}), 2.33$ (t, $J=7.5 \mathrm{~Hz}, 2 \mathrm{H}), 2.17-2.07$ (m, $1 \mathrm{H}), 1.96$ (d, $J=0.9 \mathrm{~Hz}, 3 \mathrm{H}), 1.70-1.57(\mathrm{~m}, 2 \mathrm{H}), 1.38-1.21(\mathrm{~m}, 26 \mathrm{H}), 0.94(\mathrm{~s}$, $9 \mathrm{H}), 0.98-0.85(\mathrm{~m}, 3 \mathrm{H}), 0.14(\mathrm{~s}, 3 \mathrm{H}), 0.14(\mathrm{~s}, 3 \mathrm{H}) .{ }^{13} \mathrm{C}-\mathrm{NMR}$ $\left(75.5 \mathrm{MHz}, \mathrm{CDCl}_{3}\right) \delta(\mathrm{ppm}) 173.6,163.4,151.1,137.0,133.3$, $129.3,128.4,127.6,110.5,85.5,75.3,63.7,44.6,38.1,34.3,32.0$, 29.8, 29.7, 29.5, 29.4, 29.3, 29.2, 26.0, 24.9, 22.8, 18.4, 14.2, 13.3, -5.3, -5.4. Analytical Data Are Consistent With the Literature (Cunha et al., 2020).

\section{Synthesis of Compound 5}

To a solution of compound 3 ( 1 eq., $1.39 \mathrm{~g}, 2.03 \mathrm{mmol}$ ) into dry THF $(20 \mathrm{ml})$ was added at $0^{\circ} \mathrm{C}$, under argon the TBAF (1.2 eq., $0.590 \mathrm{ml}, 2.03 \mathrm{mmol})$. The reaction mixture was stirred at $0^{\circ} \mathrm{C}$ for $3 \mathrm{~h}$ and then quenched with water $(20 \mathrm{ml})$. The aqueous phase was extracted three times with DCM $(3 \times 30 \mathrm{ml})$ and the combined organic phases were dried over $\mathrm{Na}_{2} \mathrm{SO}_{4}$ before concentration under reduced pressure. The crude product was purified by flash chromatography over silica gel (Pentane/EtOAc: $70 / 30$ ) to provide compound 5 as a white foam $(0.821 \mathrm{~g}, 71 \%)$.

$\mathrm{R}_{\mathrm{f}}=0.3$ (Pentane/EtOAc: $\left.70 / 30\right) .{ }^{1} \mathrm{H}-\mathrm{NMR}\left(300 \mathrm{MHz}, \mathrm{CDCl}_{3}\right)$ $\delta(\mathrm{ppm}) 7.59(\mathrm{~d}, J=1.2 \mathrm{~Hz}, 1 \mathrm{H}), 7.50-7.44(\mathrm{~m}, 2 \mathrm{H}), 7.33-7.21(\mathrm{~m}$, $3 \mathrm{H}), 6.31(\mathrm{t}, J=7.2 \mathrm{~Hz}, 1 \mathrm{H}), 5.37-5.31(\mathrm{~m}, 1 \mathrm{H}), 5.18-5.07(\mathrm{~m}$, $2 \mathrm{H}), 4.09-4.04(\mathrm{~m}, 1 \mathrm{H}), 3.94-3.83(\mathrm{~m}, 2 \mathrm{H}), 3.04$ (brs, $1 \mathrm{H})$, $2.41-2.28(\mathrm{~m}, 4 \mathrm{H}), 1.92(\mathrm{~d}, J=0.6 \mathrm{~Hz}, 3 \mathrm{H}), 1.69-1.54(\mathrm{~m}$, $2 \mathrm{H}), 1.40-1.15(\mathrm{~m}, 26 \mathrm{H}), 0.94-0.85(\mathrm{~m}, 3 \mathrm{H})$.

${ }^{13} \mathrm{C}-\mathrm{NMR}\left(75.5 \mathrm{MHz}, \mathrm{CDCl}_{3}\right) \delta(\mathrm{ppm}) 173.7,163.5,151.1$, $136.8,134.5,129.2,128.5,127.7,110.7,86.6,85.2,74.7,62.7,44.6$, $37.4,34.2$, 32.1, 29.8, 29.7, 29.7, 29.5, 29.4, 29.3, 29.2, 24.9, 22.8, 14.2, 13.5. Analytical Data Are Consistent With the Literature (Cunha et al., 2020). 


\section{Synthesis of Compound 7}

To a suspension of nucleolipid 5 (1eq., $500 \mathrm{mg}, 0.88 \mathrm{mmol}$ ) into dry Toluene $(10 \mathrm{ml})$, were added under argon the succinic anhydride (1eq., $88 \mathrm{mg}, 0.88 \mathrm{mmol}$ ) and the DMAP (0.1 eq., $10 \mathrm{mg}, 0.088 \mathrm{mmol})$. The reaction mixture was heated at $140^{\circ} \mathrm{C}$ and stirred for $2 \mathrm{~h}$ before concentration under reduced pressure. The crude product was purified by flash chromatography over silica gel (Toluene/EtOAc: $80 / 20$ ) to provide compound 7 as a colorless gum (350 mg, 60\%).

$\mathrm{R}_{\mathrm{f}}=0.1$ (Toluene/Acetone: 80/20). IR (ATR) $v \max \left(\mathrm{cm}^{-1}\right)$ 2924, 2857, 1835, 1717, 1649, 1563, 1455, 1357, 1254, 1159, 1100, 1004, 926, 828, 752, 706, 620, 534. ${ }^{1} \mathrm{H}-\mathrm{NMR}\left(300 \mathrm{MHz}, \mathrm{CDCl}_{3}\right) \delta$ (ppm) 7.54-7.41 (m, 2H), 7.36-7.19 (m, 4H), 6.33 (dd, $J=5.7$, $8.7 \mathrm{~Hz}, 1 \mathrm{H}), 5.25-5.04(\mathrm{~m}, 3 \mathrm{H}), 4.38$ (ddd, $J=4.5,12.3,16.2 \mathrm{~Hz}$, $1 \mathrm{H}), 4.27-4.15(\mathrm{~m}, 1 \mathrm{H}), 2.77-2.58(\mathrm{~m}, 4 \mathrm{H}), 2.44(\mathrm{dd}, J=5.4,14.1$ $\mathrm{Hz}, 1 \mathrm{H}), 2.31$ (appearing $\mathrm{t}, J=7.2,7.8 \mathrm{~Hz}, 2 \mathrm{H}), 2.21-2.05(\mathrm{~m}, 1 \mathrm{H})$, 1.93 (brs, 3H), 1.69-1.54 (m, 2H), 1.39-1.18 (m, 24H), 0.95-0.81 (m, 3H). ${ }^{13} \mathrm{C}-\mathrm{NMR}\left(75.5 \mathrm{MHz}, \mathrm{CDCl}_{3}\right) \delta$ (ppm) 177.1, 173.5, $171.8,163.4,151.0,136.8,132.9,129.3,128.5,127.7,110.9,85.6$, 82.2, 74.0, 64.2, 44.7, 37.6, 34.2, 32.0, 29.8, 29.7, 29.5, 28.8, 28.7, 24.9, 22.8, 14.2, 13.5. HRMS (ESI): Calcd. for $\mathrm{C}_{37} \mathrm{H}_{54} \mathrm{~N}_{2} \mathrm{O}_{9}$ $[\mathrm{M}+\mathrm{H}]^{+}$671.38293, found 671.39051 .

\section{Synthesis of Compound 4}

To a solution of compound 2 ( 1 eq., $2.1 \mathrm{~g}, 5.3 \mathrm{mmol}$ ) into dry DCM $(30 \mathrm{ml})$, was added under argon the arachidic acid (1.5 eq., 2.5, $8.0 \mathrm{mmol}$ ) the EDC. $\mathrm{HCl}(1.5$ eq., $1.53 \mathrm{~g}, 8.0 \mathrm{mmol}$ ) and the DMAP (0.7 eq., $0.46 \mathrm{~g}, 3.7 \mathrm{mmol}$ ). The reaction mixture was stirred at room temperature for $48 \mathrm{~h}$ and then quenched with water $(30 \mathrm{ml})$. The aqueous phase was extracted three times with DCM $(3 \times 30 \mathrm{ml})$, and the combined organic phases were dried over $\mathrm{Na}_{2} \mathrm{SO}_{4}$ before concentration under reduced pressure. The crude product was purified by flash chromatography over silica gel (Pentane/EtOAc: 70/30) to provide 4 as a white foam (3.64 g, quantitative yield).

$\mathrm{R}_{\mathrm{f}}=0.9$ (Pentane/EtOAc: 70/30). IR (ATR) vmax $\left(\mathrm{cm}^{-1}\right)$ 2926, 2855, 2254, 1736, 1703, 1668, 1645, 1496, 1464, 1404, 1352, 1321, 1294, 1259, 1166, 1126, 1079, 1004, 903, 833, 780, 701, 648, 616, 536, 495, 465. ${ }^{1} \mathrm{H}-\mathrm{NMR}\left(300 \mathrm{MHz}, \mathrm{CDCl}_{3}\right) \delta(\mathrm{ppm}) 7.55(\mathrm{~d}, J=$ $0.9 \mathrm{~Hz}, 1 \mathrm{H}), 7.59-7.47(\mathrm{~m}, 2 \mathrm{H}), 7.36-7.22(\mathrm{~m}, 3 \mathrm{H}), 6.42(\mathrm{dd}, J=$ 5.1, 9.3 Hz, 1H), 5.29-5.23 (m, 1H), 5.21-5.08 (m, 2H), 4.11-4.06 $(\mathrm{m}, 1 \mathrm{H}), 3.98-3.86(\mathrm{~m}, 2 \mathrm{H}), 2.41(\mathrm{dd}, J=5.4,13.8 \mathrm{~Hz}, 1 \mathrm{H}), 2.33(\mathrm{t}$, $J=7.5 \mathrm{~Hz}, 2 \mathrm{H}), 2.18-2.03(\mathrm{~m}, 1 \mathrm{H}), 1.96(\mathrm{~d}, J=0.9 \mathrm{~Hz}, 3 \mathrm{H}), 1$. 71-1.57 (m, 2H), 1.39-1.22 (m, 32H), 0.94 (s, 9H), 0.97-0.85 (m, $3 \mathrm{H}), 0.14(\mathrm{~s}, 3 \mathrm{H}), 0.14(\mathrm{~s}, 3 \mathrm{H}) .{ }^{13} \mathrm{C}-\mathrm{NMR}\left(75.5 \mathrm{MHz}, \mathrm{CDCl}_{3}\right) \delta$ (ppm) 178.9, 173.6, 163.5, 151.1, 137.0, 133.3, 129.3, 128.5, 127.7, $110.6,85.5,75.3,63.7,44.6,38.1,34.3,32.0,29.8,29.8,29.7,29.5$, 29.5, 29.3, 29.2, 26.0, 24.9, 22.8, 18.4, 14.2, 13.4, - 5.3, -5.4. HRMS (ESI): Calcd. for $\mathrm{C}_{43} \mathrm{H}_{72} \mathrm{~N}_{2} \mathrm{O}_{6} \mathrm{Si}[\mathrm{M}+\mathrm{H}]^{+}$741.51596, found 741.52431.

\section{Synthesis of Compound 6}

To a solution of compound 4 ( 1 eq., $1.28 \mathrm{~g}, 1.73 \mathrm{mmol}$ ) into dry THF $(19 \mathrm{ml})$ was added at $0^{\circ} \mathrm{C}$, under argon the TBAF $(1.2$ eq., $0.50 \mathrm{ml}, 1.90 \mathrm{mmol})$. The reaction mixture was stirred at $0^{\circ} \mathrm{C}$ for $3 \mathrm{~h}$ and then quenched with water $(20 \mathrm{ml})$. The aqueous phase was extracted three times with DCM $(3 \times 30 \mathrm{ml})$, and the combined organic phases were dried over $\mathrm{Na}_{2} \mathrm{SO}_{4}$ before concentration under reduced pressure. The crude product was purified by flash chromatography over silica gel (Pentane/EtOAc: $70 / 30$ ) to provide the compound 6 as a white foam (720 mg, 70\%).

$\mathrm{R}_{\mathrm{f}}=0.3$ (Pentane/EtOAc: 7/3). IR (ATR) vmax $\left(\mathrm{cm}^{-1}\right) 3403$, 2918, 2852, 2057, 1987, 1938, 1832, 1786, 1711, 1635, 1461, 1358, 1235, 1170, 1096, 992, 928, 718, 615, 536, 448, 432, 407. ${ }^{1} \mathrm{H}-\mathrm{NMR}$ $\left(300 \mathrm{MHz}, \mathrm{CDCl}_{3}\right) \delta(\mathrm{ppm})$ 7.67-7.62 (m, 1H), 7.49-7.41 (m, $2 \mathrm{H}), 7.33-7.17(\mathrm{~m}, 3 \mathrm{H}), 6.32$ (appearing $\mathrm{t}, J=7.5,6.6 \mathrm{~Hz}, 1 \mathrm{H})$, 5.37-5.30 (m, 1H), $5.11(\mathrm{~s}, 2 \mathrm{H}), 4.08-4.02(\mathrm{~m}, 1 \mathrm{H}), 3.89-3.83(\mathrm{~m}$, $2 \mathrm{H}), 3.54$ (brs, $1 \mathrm{H}), 2.38-2.26(\mathrm{~m}, 2 \mathrm{H}), 1.89$ (brs, $3 \mathrm{H}), 1.68-1.56$ $(\mathrm{m}, 2 \mathrm{H}), 1.35-1.22(\mathrm{~m}, 32 \mathrm{H}), 0.92-0.83(\mathrm{~m}, 3 \mathrm{H}) .{ }^{13} \mathrm{C}-\mathrm{NMR}$ $\left(75.5 \mathrm{MHz}, \mathrm{CDCl}_{3}\right) \delta(\mathrm{ppm}) 173.6,163.5,151.0,136.7,134.6$, $129.0,128.3,127.6,110.3,86.3,85.2,74.8,62.4,44.5,31.9,29.7$, 29.6, 29.6, 29.4, 29.3, 29.2, 29.1, 24.8, 22.7, 14.1, 13.3. HRMS (ESI): Calcd. for $\mathrm{C}_{37} \mathrm{H}_{58} \mathrm{~N}_{2} \mathrm{O}_{6}[\mathrm{M}+\mathrm{H}]^{+}$627.42949, found 627.43718 .

\section{Synthesis of Compound 8}

To a suspension of nucleolipid 6 ( 1 eq., $100 \mathrm{mg}, 0.17 \mathrm{mmol}$ ) into dry toluene $(10 \mathrm{ml})$, were added under argon the succinic anhydride ( $1 \mathrm{eq}, 17 \mathrm{mg}, 0.17 \mathrm{mmol}$ ) and the DMAP (0.1 eq., $2 \mathrm{mg}, 0.017 \mathrm{mmol})$. The reaction was heated at $140^{\circ} \mathrm{C}$ and stirred for $4 \mathrm{~h}$ before concentration under reduced pressure. The crude product was purified by flash chromatography over silica gel (Toluene/EtOAc: $80 / 20$ ) to provide 8 as a colorless gum (75 mg, 66\%).

$\mathrm{R}_{\mathrm{f}}=0.1$ (Toluene/EtOAc: 8/2). IR (ATR) vmax $\left(\mathrm{cm}^{-1}\right) 2923$, $2853,1738,1705,1668,1645,1496,1454,1352,1317,1272,1247$, 1157, 1102, 1078, 1002, 909, 826, 766, 732, 700, 618, 538, 495, 466, 421. ${ }^{1} \mathrm{H}-\mathrm{NMR}\left(300 \mathrm{MHz}, \mathrm{CDCl}_{3}\right) \delta(\mathrm{ppm}) 7.54-7.43(\mathrm{~m}, 2 \mathrm{H})$, $7.38-7.22(\mathrm{~m}, 4 \mathrm{H}), 6.33(\mathrm{dd}, J=5.7,8.7 \mathrm{~Hz}, 1 \mathrm{H}), 5.26-5.06(\mathrm{~m}$, $3 \mathrm{H}), 4.37(\mathrm{ddd}, J=4.5,12.3,30.9 \mathrm{~Hz}, 2 \mathrm{H}), 4.24-4.16(\mathrm{~m}, 1 \mathrm{H})$, 2.77-2.59 (m, 4H), $2.43(\mathrm{dd}, J=5.4,14.1 \mathrm{~Hz}, 1 \mathrm{H}), 2.31(\mathrm{t}, J=$ $7.5 \mathrm{~Hz}, 2 \mathrm{H}), 2.21-2.06$ (m, 1H), 1.94 (brs, 3H), 1.71-1.53 (m, 2H), 1.41-1.18 (m, 34H), 0.93-0.81 (m, 3H); ${ }^{13} \mathrm{C}-\mathrm{NMR}(75.5 \mathrm{MHz}$, $\left.\mathrm{CDCl}_{3}\right) \delta(\mathrm{ppm}) 177.1,173.5,171.8,163.4,151.0,136.9,132.9$, $129.3,128.5,127.8,111.0,85.6,82.3,74.0,64.2,44.7,37.6,34.2$, $32.1,29.8,29.8,29.7,29.6,29.5,29.4,29.2,28.8,28.6,24.9,22.8$, 14.3, 13.5. HRMS (ESI): Calcd. for $\mathrm{C}_{41} \mathrm{H}_{62} \mathrm{~N}_{2} \mathrm{O}_{9}[\mathrm{M}+\mathrm{H}]+$ 727.44553 , found 727.45319 .

\section{Nanoemulsion Preparation and Characterization NEs Formulation}

For all experiments, O/W NE were used as freshly prepared, formulated with medium chain triglyceride oil $\left(\mathrm{Miglyol}^{\circledR}\right.$ $812 \mathrm{~N}$ ) and two surfactants. To obtain the oily phase, $12 \mathrm{mg}$ egg lecithin (Lipoid ${ }^{\circledR}$ E80) were dispersed in $200 \mathrm{mg}$ $70^{\circ} \mathrm{C}$ heated oil phase Miglyol ${ }^{\circledR} 812 \mathrm{~N}$. The aqueous phase was composed of a dispersion of $25 \mathrm{mg}$ Polysorbate 80 (Tween ${ }^{\circledR}$ $80)$ in the $70^{\circ} \mathrm{C}$ heated $800 \mathrm{mg}$ Milli-Q water. NE-5 to NE-8 were loaded respectively with compounds 5 to 8 , solubilized at various final concentrations in NEs at $1.8 \times 10^{4} \mu \mathrm{M}$ for NL $5 ; 1.6 \times 10^{4} \mu \mathrm{M}$ for NL $6 ; 1.5,4.5$ and $10.5 \times 10^{4} \mu \mathrm{M}$ for NL 7; 1.4 and $4.2 \times 10^{4} \mu \mathrm{M}$ for NL 8 . To adjust osmolality for in vitro experiments, Glycerol at $2.25 \%$ was added to the 
TABLE 1 | Composition of NEs loaded with acid-based NLs.

\begin{tabular}{|c|c|}
\hline & NE-NL \\
\hline $\mathrm{NL}$ content (\%) w/w $\mathrm{w}^{\mathrm{a}}$ & $1-7 \%$ \\
\hline Lipoïd $^{\circledast}$ E80 & $1.2 \%$ \\
\hline Miglyol $812 \mathrm{~N}$ & $20 \%$ \\
\hline Tween $^{(1)} 80$ & $2.5 \%$ \\
\hline Glycerol & $2.25 \%$ \\
\hline $\mathrm{H}_{2} \mathrm{O} q s$ & $100 \%$ \\
\hline
\end{tabular}

aqueous phase. Phase inversion, with previously prepared and heated phases and homogenization by sonication (Sonic Vibra Cell-VC 250), afforded the emulsion with submicron size range oil droplets. NEs typical composition in $\% \mathrm{w} / \mathrm{w}$ is given in Table 1.

\section{NEs Characterization}

Physical characteristics of all NEs were assessed by dynamic light scattering (DLS) using Malvern Instruments (Zetasizer Nano ZS). NEs were diluted at $1 / 2500(\mathrm{v} / \mathrm{v})$, and the average size and the polydispersity index were determined by three independent measurements performed at $25^{\circ} \mathrm{C}$. To analyze the $\zeta$-potential, NEs were diluted at $1 / 1500(\mathrm{v} / \mathrm{v})$, and measurements were performed using Zetasizer Nano ZS coupled with a folded capillary cell (DTS1060) from Malvern Instruments. Colloidal stability of loaded NEs was demonstrated for at least 3 months. The droplet's mean diameter, index of polydispersity, and $\zeta$-potential remained stable during the study. The macroscopic aspect showed no phase separation nor creaming during all study time.

\section{Cell Culture and Cell Viability Assay of Nucleolipid-Loaded Nanoemulsions}

Human neuroblastoma cell lines BE(2)-M17 were obtained from ATCC (CRL-2267) (Filograna et al., 2015) and grown in OPTIMEM (Life Technologies, 31985-047) plus 10\% fetal bovine serum (Sigma-Aldrich). ATP13A2 stable knockdown BE-(2)-M17 (shATP13A2(403-1)) human dopaminergic neuroblastoma cells were maintained at $37^{\circ} \mathrm{C}$ in $5 \% \mathrm{CO}_{2}$ in OPTIMEM supplemented with $10 \%$ fetal calf serum, $1 \%$ penicillin/streptomycin, and $2 \mathrm{mg} / \mathrm{ml}$ puromycin (SigmaAldrich). For NE treatments, cells were grown at $70-80 \%$ confluence and treated for $24 \mathrm{~h}$ with $1 \mu \mathrm{L}$ of $\mathrm{NE}$ diluted to 1/1000. Each experiment was reproduced at least in three independent series. Cell viability was estimated by MTT assay (ATCC/LGC Promochem) following manufacturer instructions.

\section{Lysosomal pH Measurement}

Quantification of lysosomal $\mathrm{pH}$ was determined using dextran conjugates LysoSensor Yellow/Blue DND-160 (Life Technologies) and was performed as previously described (Bourdenx et al., 2016; Dehay et al., 2012). Briefly, control and mutant ATP13A2 cells were grown in their respective media. Cells were then trypsinized, harvested $\left(1 \times 10^{6}\right.$ cells/ $\mathrm{mL}$ ), and loaded with $1 \mathrm{mg} / \mathrm{ml}$ of LysoSensor-dextran for $1 \mathrm{~h}$ at $37^{\circ} \mathrm{C}$ with $5 \% \mathrm{CO}_{2}$. The cells were then washed $3 \times$ in HBSS (Gibco, 14060) and aliquoted at $100 \mathrm{ml}$ into a black 96-well microplate. $\mathrm{pH}$ calibration was performed as previously described. Wild-type and mutant cells were treated with $10 \mathrm{mM}$ monensin (Sigma-Aldrich) and $10 \mathrm{mM}$ nigericin (Sigma-Aldrich) in MES buffer ( $5 \mathrm{mM} \mathrm{NaCl}, 115 \mathrm{mM} \mathrm{KCl}$, $1.3 \mathrm{mM} \mathrm{MgSO}_{4}, 25 \mathrm{mM} \mathrm{MES}$ ), with the $\mathrm{pH}$ adjusted to a range from 3.5 to 7.0. The samples were read in a FLUOstar Optima fluorimeter (BMG Labtech, Champigny sur Marne, France) with excitation at $355 \mathrm{~nm}$. The ratio of emission $440 / 535 \mathrm{~nm}$ was then calculated for each sample. The $\mathrm{pH}$ values were determined from the standard linear curve generated via the $\mathrm{pH}$ calibration samples.

\section{RESULTS AND DISCUSSION}

\section{Design and Synthesis of the Nucleolipid-Based Platform}

Two original NLs (compounds 7 and 8) bearing a succinic acid moiety at the 5' position and respectively palmitate and arachidate esters at the $3^{\prime}$ position, were designed, synthesized, and biologically evaluated as lysosomal $\mathrm{pH}$ modulators. Commercially available thymidine was used as a synthetic platform, and key positions were conveniently functionalized step-by-step (Scheme 1). Previous work has shown that a benzyl group, conveniently inserted at the N-3 position, increased sufficiently the lipophilicity to allow the compound to be solubilized in oil and then provide its subsequent incorporation into an O/W NE (Cunha et al., 2020). A benzyl group was then selectively introduced at the $\mathrm{N}-3$ position of thymidine, using a microwave-assisted activation step as described in the literature (Hamoud et al., 2018). Then the hydroxyl at $5^{\prime}$ position was protected as a silylated ether. A classical esterification step with two different monocatenar fatty chains (palmitic, arachidic acids) at $3^{\prime}$ position provided compounds 3 and 4 in quantitative yields. The choice of the optimal length of the fatty chains was made in agreement with the previous results (Cunha et al., 2020). The silylated ether was then cleaved under classical conditions before the last step to functionalize the hydroxyl at $5^{\prime}$ as succinate. Various attempts to provide selective esterification with succinic acid became unsuccessful; succinate was then introduced by opening succinic anhydride under robust desymmetrization conditions (Catry and Madder, 2007). This straightforward five-step sequence provided efficiently acidic NLs 7-8 with fatty chains of 16 and 20 carbons, respectively. Under physiological conditions, compounds 7-8 should be cleaved to release the active succinic acid and regenerate the corresponding precursors 5 and 6 , respectively. 5 and 6 are themselves also degradable, releasing palmitic and arachidic acid.

$\mathrm{O} / \mathrm{W}$ NEs have an excellent loading capacity for hydrophobic drugs while improving their stability compared to other lipidic formulations, i.e., liposomes 


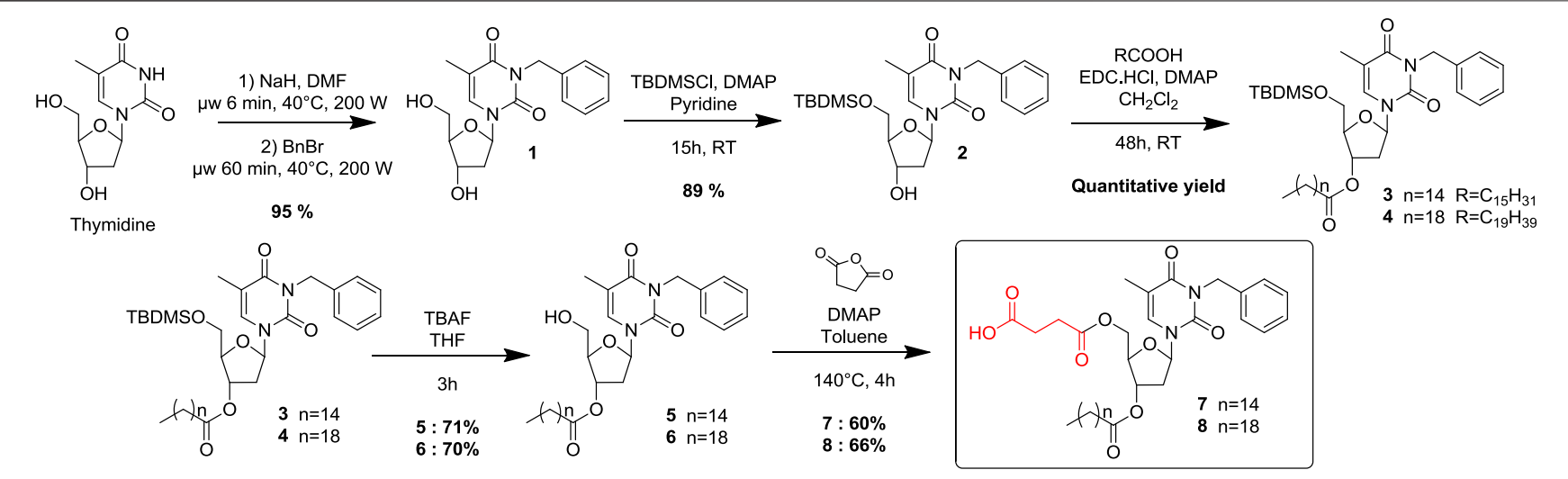

SCHEME 1 | Synthetic pathway to generate NL 7-8.

TABLE 2 | Physico-chemical characteristics of selected NEs: unloaded one, and those loaded with the effective NL.

\begin{tabular}{|c|c|c|c|c|c|c|}
\hline & \multicolumn{2}{|c|}{ NE-O } & \multicolumn{2}{|c|}{ NE-8-1\% } & \multicolumn{2}{|c|}{ NE-8-3\% } \\
\hline & TO & 3 months & TO & 3 months & TO & 3 months \\
\hline Droplets mean diameter (nm) & $175.2 \pm 1.36$ & $175.9 \pm 2.48$ & $156.5 \pm 2.71$ & $155.6 \pm 1.56$ & $198.8 \pm 2.65$ & $193.6 \pm 3.17$ \\
\hline Polydispersity index & 0.125 & 0.111 & 0.099 & 0.087 & 0.135 & 0.124 \\
\hline Zeta potential (mv) & $-31.2 \pm 1.8$ & $-22.9 \pm 0.1$ & $-34.4 \pm 1.0$ & $-28.2 \pm 2.3$ & $-33.8 \pm 0.8$ & $-29.3 \pm 1.2$ \\
\hline
\end{tabular}

used in clinics (Sainsbury et al., 2014). Indeed, the very small droplet size in the nanometric scale NEs makes them suitable for intravenous drug delivery. All NEs were formulated with $20 \%$ medium-chain triglyceride oil (Miglyol ${ }^{\circledR} 812 \mathrm{~N}$ ), $1.2 \%$ lecithin $80,2.5 \%$ polysorbate 80 surfactant. An unloaded NE, NE- 0 was used as a control. NLs acids 7-8 and intermediates 5-6 were respectively loaded in NEs NE-5, NE-6, NE-7, NE-8 with final concentrations from 1 to $7 \%(w / w)$, depending on their solubility in oil. The loading was successfully performed without altering the physical parameters, i.e., mean droplets size, granulometric profiles, and zeta potential, compared to the unloaded NE. However, a slight increase of the NE's hydrodynamic mean diameter was observed for the highest concentrations of the loaded NLs for both NE-8 and NE-7 (data not shown). This modification did not alter the granulometric profile that stayed narrow with PDI below 0.2 or the system's stability. Finally, compared to commonly commercialized intravenous drug-loaded NEs such as Propofol, exhibiting mean diameters between 250 and $280 \mathrm{~nm}$, the slight increase of the hydrodynamic diameter did not alter the capacity of the system to be intravenously administered (Patil et al., 2019).

Analysis by DLS displayed an average diameter lower than $200 \mathrm{~nm}$. This size is consistent for nanoobjects to be easily uptaken into cells and to colocalize subcellular organelles. A monodisperse distribution with a submicronic size range and $\zeta$-potential values around $-35 \mathrm{mV}$ were also measured. Negative

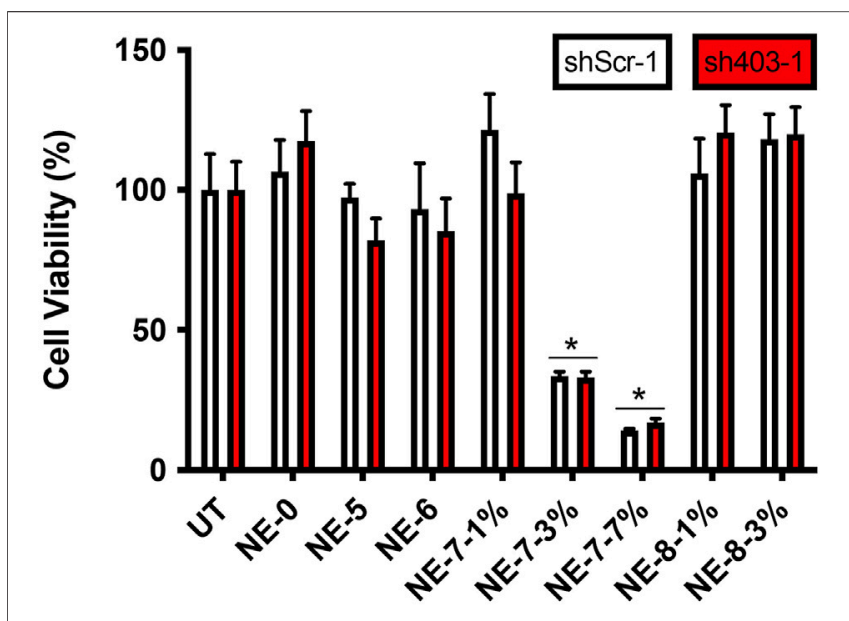

FIGURE 2 | Cell viability in control (shScr-1) and ATP13A2-depleted (sh403-1) M17 cells, in the absence (UT) or presence of NE-0, NE-5, NE-6, $\mathrm{NE}-7$ and NE-8 after $24 \mathrm{~h}{ }^{*} p<0.05$ compared with untreated cells.

zeta potential is compatible with brain targeting and is recognized as non-toxic in comparison to cationic NEs (Lockman et al., 2004). Thus, negatively charged nanocarriers are privileged. All our formulations exhibited stable parameters for at least 3 months, as shown by compound 8 being the most effective (NE-8-1\% was loaded with $1 \% \mathrm{w} / \mathrm{w}$ of NL $8, \mathrm{NE}-8-3 \%$ was loaded with $3 \% \mathrm{w} / \mathrm{w}$ of NL 8 ). (Table 2). 


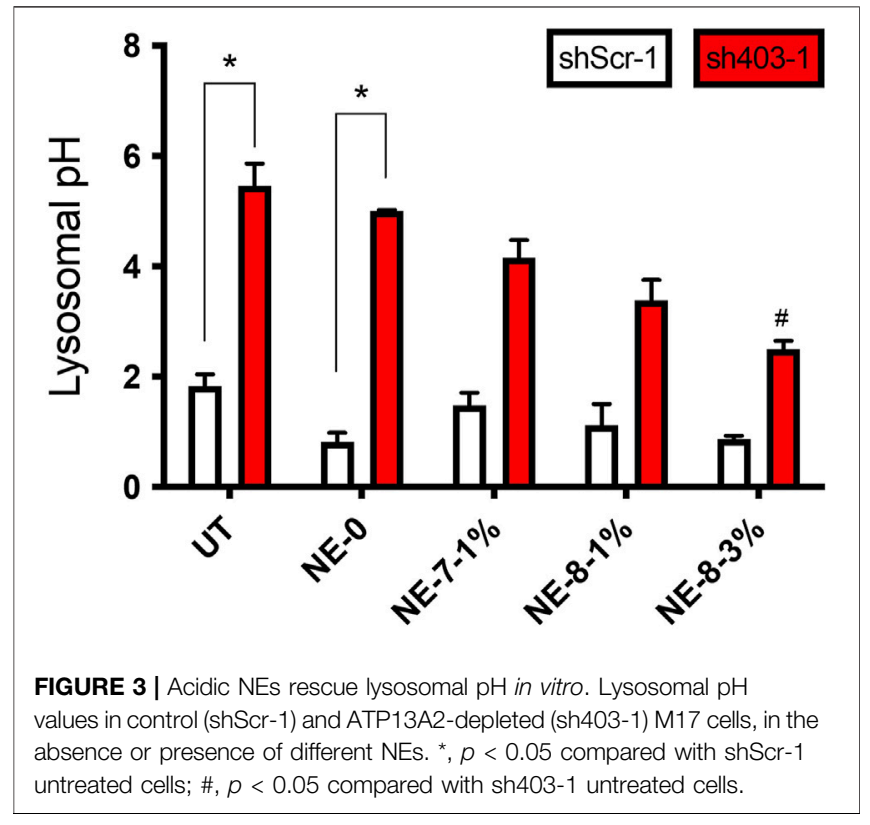

\section{Acidic Nanoemulsions Rescue Lysosomal pH in Vitro}

Succinic acid is a biocompatible dicarboxylic acid present in all living organisms. This molecule is involved in cellular metabolism, particularly in the lipid metabolism. To investigate whether our NEs, loaded with our succinic-acidbased prodrugs at various concentrations, exhibit a cellular cytotoxicity, human neuroblastoma cells were exposed to them for $24 \mathrm{~h}$. First, in vitro viability assays, with NEs diluted to $1 / 1000$, confirmed that acidic NE-8 loaded with the arachidic derivative NL 8 ( 1 and $3 \% \mathrm{w} / \mathrm{w}$ concentrations) did not induce cell death for the loading rates tested (Figure 2). Moreover, NE-5 and NE-6, loaded respectively with 5 and 6 , intermediates resulting from the partial degradation of the final prodrugs, did not induce any cytotoxicity either. However, the biological evaluation showed cytotoxicity for NE-7, bearing a palmitic acid chain at $3^{\prime}$ position, for the nanoemulsions loaded with 3 and $7 \% \mathrm{w} / \mathrm{w}$ of NL 7 . It was not possible to perform viability assays with NE- 5 and NE- 6 at the same $3 \% \mathrm{w} / \mathrm{w}$ concentration as NE-7-3\%, making it challenging to explain the cytotoxicity observed for NE-7. Further biological work will be necessary to raise this point. Thus, the results highlight the biocompatibility of our NEs, paving the way to test their effect on the lysosomal $\mathrm{pH}$ assessment.

Lysosomal $\mathrm{pH}$ was assessed on M17 neuronal cell line stably depleted of ATP13A2, a lysosomal type 5 P-type ATPase. This cellular model displays abnormally high $\mathrm{pH}$ in their lysosomes since an impairment of ATP13A2 function increases lysosomal $\mathrm{pH}$ (Usenovic and Krainc, 2012; Dehay et al., 2013; Bento et al., 2016; Bourdenx et al., 2016). In vitro investigations on the effect of NL$\mathrm{NE}$ on lysosomal $\mathrm{pH}$ highlighted that $\mathrm{NE}$ loaded with the longest fatty chains-based NLs turned out to be adequate to recover the acidic medium to normal levels $(\mathrm{pH}=3)$, without lowering the lysosomal pH of control cells. The NE loaded incubated for $24 \mathrm{~h}$, allowed a significant restoration of the lysosomal pH (Figure 3). It is assumed that the final acidification resulting from the in vitro degradation of the NL 7-8, is potentially due to the release of a mixture of the constitutive acids, including succinic acid. It looks like an active substance concentration of $7 \mu \mathrm{M}$ starts to acidify the medium, while a concentration of $40 \mu \mathrm{M}$ allows a total recovery of the lysosomal acidification defects. These results are promising for using such nanocarriers as tools to rescue lysosomal function in vitro in ATP13A2-knockdown cells with acidic NL-based NEs.

\section{CONCLUSION}

A functional lysosome is crucial for maintaining proper cellular and neuronal function. Hence, targeting lysosomal impairment is becoming an increasingly important goal in developing treatments for many diseases including neurodegenerative diseases. In this context, restoring its dysfunctional acidic medium could provide a therapeutic option. To overcome the shortcomings of the current chemical arsenal mainly based on

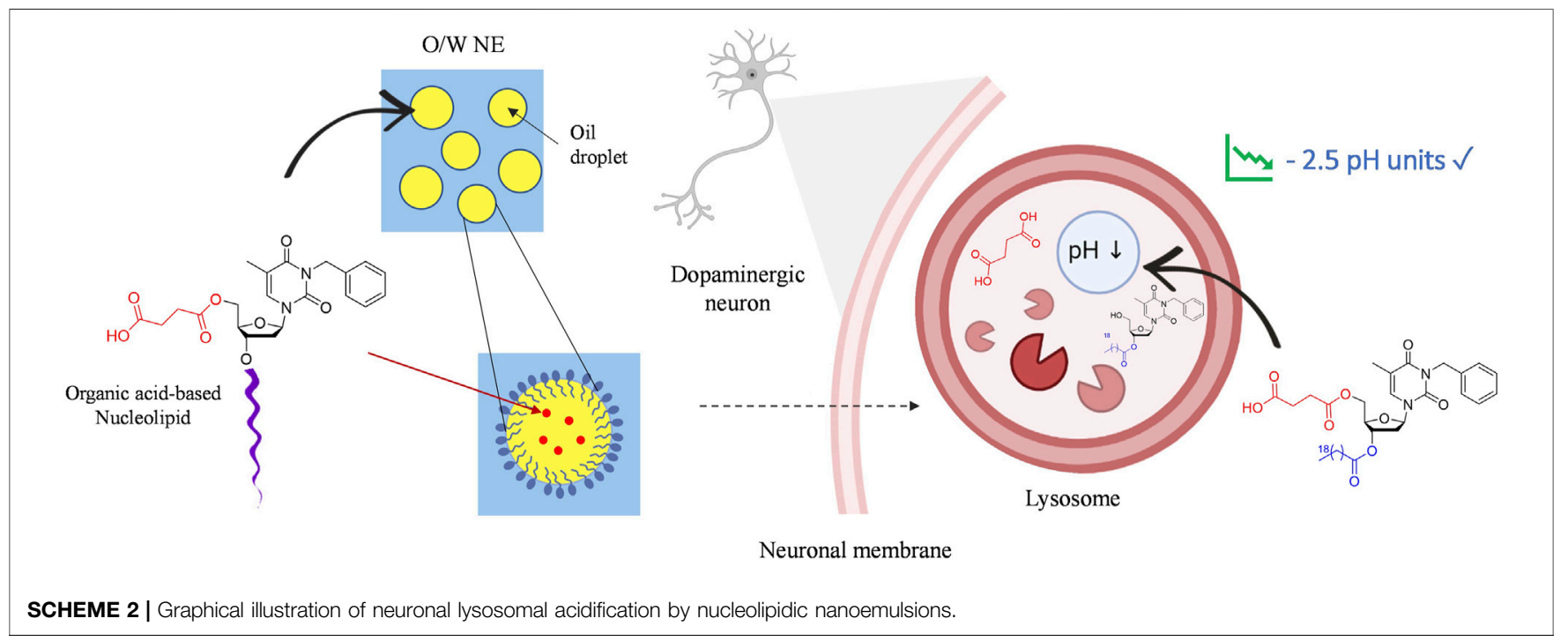


PLGA polymeric NPs, the first low molecular weight acidbased NL nanocarriers were developed to formulate and carry the biocompatible organic succinic diacid to the lysosome. A straightforward five-step sequence, starting from thymidine, afforded acidic NLs 7-8, bearing 16 and 20 carbons saturated fatty chains respectively in good overall yields. O/W NEs were loaded with NLs acids 7-8 and their precursors 5-6 to provide stable nanosystems: NE-5, NE-6, NE-7, NE-8. NEs' formulation was designed with commonly used intravenous excipients to help the further transfer from laboratory bench side to patient bedside. In vitro, NE-8-3\% ( $c=40 \mu \mathrm{M}$ of active substance), was shown not only to cross the membrane without any cytotoxicity but also to completely restore the acidic $\mathrm{pH}$ of the lysosome in a genetic cell model of Parkinson's disease.

This very positive result, equivalent to that obtained with PLGA, shows that it is possible to overcome the limits of the use of this polymer. Varying the nature of the organic acid could provide a released acidification modulation. Moreover, the NL was developed as a synthetic platform that can be tuned to carry other active ingredients. Further in vivo studies will focus on the transposability of this innovative therapeutic approach and evaluate the ability of the DNA-based nanocarrier to cross the BBB. A positive outcome would allow us to consider NL functionalization with suitable active substances for other neurodegenerative diseases.

The authors declare that the research was conducted in the absence of any commercial or financial relationships that could be construed as a potential conflict of interest.

\section{DATA AVAILABILITY STATEMENT}

The original contributions presented in the study are included in the article/Supplementary Material, further inquiries can be directed to the corresponding authors.

\section{REFERENCES}

Benizri, S., Ferey, L., Alies, B., Mebarek, N., Vacher, G., Appavoo, A., et al. (2018). Nucleoside-Lipid-Based Nanocarriers for Sorafenib Delivery. Nanoscale Res. Lett. 13, 17. doi:10.1186/s11671-017-2420-2

Bento, C. F., Ashkenazi, A., Jimenez-Sanchez, M., and Rubinsztein, D. C. (2016). The Parkinson's Disease-Associated Genes ATP13A2 and SYT11 Regulate Autophagy via a Common Pathway. Nat. Commun. 7, 11803. doi:10.1038/ncomms11803

Bonam, S. R., Wang, F., and Muller, S. (2019). Lysosomes as a Therapeutic Target. Nat. Rev. Drug Discov. 18, 923-948. doi:10.1038/s41573-019-0036-1

Bourdenx, M., Daniel, J., Genin, E., Soria, F. N., Blanchard-Desce, M., Bezard, E., et al. (2016). Nanoparticles Restore Lysosomal Acidification Defects: Implications for Parkinson and Other Lysosomal-Related Diseases. Autophagy 12, 472-483. doi:10.1080/15548627.2015.1136769

Catry, M., and Madder, A. (2007). Synthesis of Functionalised Nucleosides for Incorporation into Nucleic Acid-Based Serine Protease Mimics. Molecules 12, 114-129. doi:10.3390/12010114

Colacurcio, D. J., and Nixon, R. A. (2016). Disorders of Lysosomal AcidificationThe Emerging Role of V-ATPase in Aging and Neurodegenerative Disease. Ageing Res. Rev. 32, 75-88. doi:10.1016/j.arr.2016.05.004

Cunha, A., Gaubert, A., Latxague, L., and Dehay, B. (2021). PLGA-based Nanoparticles for Neuroprotective Drug Delivery in

\section{AUTHOR CONTRIBUTIONS}

$\mathrm{BD}$ and $\mathrm{VD}$ are co-corresponding authors. $\mathrm{MB}$ and $\mathrm{BD}$ carried out experiments. VD designed the synthetic nucleolipid acid target and the synthetic pathway, SC-M designed the formulation and physicochemistry experiments, and $\mathrm{BD}$ designed the biological experiments. $\mathrm{BD}, \mathrm{SC}-\mathrm{M}$, and $\mathrm{VD}$ analyzed the data and wrote the manuscript. $\mathrm{MB}, \mathrm{VD}$ and $\mathrm{BD}$ wrote the experimental part. $\mathrm{PB}$ proofread the manuscript. BD, SC-M, VD and PB secured the funding. All authors read and approved the manuscript.

\section{FUNDING}

This work was supported by an IDEX Emergence Grant number OPE-2018-410 (BD). STS department (Sciences and Technologies for Health) of the University of Bordeaux provided open access publication fees (VD).

\section{ACKNOWLEDGMENTS}

$M B$ is a recipient of an MSER fellowship (France). INSERM, CNRS, and the University of Bordeaux provided financial and infrastructural support. We thank Marie-Laure Thiolat for technical assistance in cell culture. The authors gratefully acknowledge Anceline Willemaers for her support and for proofreading the manuscript.

\section{SUPPLEMENTARY MATERIAL}

The Supplementary Material for this article can be found online at: https://www.frontiersin.org/articles/10.3389/fchem.2021.736554/ full\#supplementary-material

Neurodegenerative Diseases. Pharmaceutics 13, 1042. doi:10.3390/ pharmaceutics 13071042

Cunha, A., Prévot, G., Mousli, Y., Barthélémy, P., Crauste-Manciet, S., Dehay, B., et al. (2020). Synthesis and Intracellular Uptake of Rhodamine-Nucleolipid Conjugates into a Nanoemulsion Vehicle. ACS Omega 5, 5815-5823. doi:10.1021/acsomega.9b03992

Dehay, B., Bove, J., Rodriguez-Muela, N., Perier, C., Recasens, A., Boya, P., et al. (2010). Pathogenic Lysosomal Depletion in Parkinson's Disease. J. Neurosci. 30, 12535-12544. doi:10.1523/JNEUROSCI.1920-10.2010

Dehay, B., Martinez-Vicente, M., Caldwell, G. A., Caldwell, K. A., Yue, Z., Cookson, M. R., et al. (2013). Lysosomal Impairment in Parkinson's Disease. Mov Disord. 28, 725-732. doi: $10.1002 / \mathrm{mds} .25462$

Dehay, B., Ramirez, A., Martinez-Vicente, M., Perier, C., Canron, M.-H., Doudnikoff, E., et al. (2012). Loss of P-type ATPase ATP13A2/PARK9 Function Induces General Lysosomal Deficiency and Leads to Parkinson Disease Neurodegeneration. Proc. Natl. Acad. Sci. 109, 9611-9616. doi:10.1073/pnas.1112368109

Edelmann, M. J., and Maegawa, G. H. B. (2020). CNS-targeting Therapies for Lysosomal Storage Diseases: Current Advances and Challenges. Front. Mol. Biosci. 7, 559804. doi:10.3389/fmolb.2020.559804

Filograna, R., Civiero, L., Ferrari, V., Codolo, G., Greggio, E., Bubacco, L., et al. (2015). Analysis of the Catecholaminergic Phenotype in Human SH-Sy5y and BE(2)-M17 Neuroblastoma Cell Lines upon Differentiation. PLoS ONE 10 (8), e0136769. doi:10.1371/journal.pone.0136769 
Gissot, A., Camplo, M., Grinstaff, M. W., and Barthélémy, P. (2008). Nucleoside, Nucleotide and Oligonucleotide Based Amphiphiles: a Successful Marriage of Nucleic Acids with Lipids. Org. Biomol. Chem. 6, 1324-1333. doi:10.1039/ b719280k

Hafner Česen, M., Pegan, K., Špes, A., and Turk, B. (2012). Lysosomal Pathways to Cell Death and Their Therapeutic Applications. Exp. Cel Res. 318, 1245-1251. doi:10.1016/j.yexcr.2012.03.005

Hamoud, A., Barthélémy, P., and Desvergnes, V. (2018). An Organocatalyzed Stetter Reaction as a Bio-Inspired Tool for the Synthesis of Nucleic AcidBased Bioconjugates. Org. Biomol. Chem. 16, 1760-1769. doi:10.1039/ C8OB00192H

Karami, Z., Saghatchi Zanjani, M. R., and Hamidi, M. (2019). Nanoemulsions in CNS Drug Delivery: Recent Developments, Impacts and Challenges. Drug Discov. TodayToday 24, 1104-1115. doi:10.1016/ j.drudis.2019.03.021

Kawai, A., Uchiyama, H., Takano, S., Nakamura, N., and Ohkuma, S. (2007). Autophagosome-lysosome Fusion Depends on the $\mathrm{pH}$ in Acidic Compartments in CHO Cells. Autophagy 3, 154-157. doi:10.4161/auto.3634

Koh, J.-Y., Kim, H. N., Hwang, J. J., Kim, Y.-H., and Park, S. E. (2019). Lysosomal Dysfunction in Proteinopathic Neurodegenerative Disorders: Possible Therapeutic Roles of cAMP and Zinc. Mol. Brain 12, 18. doi:10.1186/ s13041-019-0439-2

Lie, P. P. Y., and Nixon, R. A. (2019). Lysosome Trafficking and Signaling in Health and Neurodegenerative Diseases. Neurobiol. Dis. 122, 94-105. doi:10.1016/ j.nbd.2018.05.015

Lockman, P. R., Koziara, J. M., Mumper, R. J., and Allen, D. D. (2004). Nanoparticle Surface Charges Alter Blood-Brain Barrier Integrity and Permeability. J. Drug Target. 12, 635-641. doi:10.1080/10611860400015936

Luzio, J. P., Pryor, P. R., and Bright, N. A. (2007). Lysosomes: Fusion and Function. Nat. Rev. Mol. Cel Biol 8, 622-632. doi:10.1038/nrm2217

Marques, A. R. A., and Saftig, P. (2019). Lysosomal Storage Disorders - Challenges, Concepts and Avenues for Therapy: beyond Rare Diseases. J. Cel Sci 132, jcs2211739. doi:10.1242/jcs.221739

Patil, S. M., Li, V., Peng, J., Kozak, D., Xu, J., Cai, B., et al. (2019). A Simple and Noninvasive DOSY NMR Method for Droplet Size Measurement of Intact OilIn-Water Emulsion Drug Products. J. Pharm. Sci. 108, 815-820. doi:10.1016/ j.xphs.2018.09.027

Peng, W., Minakaki, G., Nguyen, M., and Krainc, D. (2019). Preserving Lysosomal Function in the Aging Brain: Insights from Neurodegeneration. Neurotherapeutics 16, 611-634. doi:10.1007/s13311-019-00742-3

Prévot, G., Soria, F. N., Thiolat, M.-L., Daniel, J., Verlhac, J. B., BlanchardDesce, M., et al. (2018). Harnessing Lysosomal pH through PLGA Nanoemulsion as a Treatment of Lysosomal-Related Neurodegenerative Diseases. Bioconjug. Chem. 29, 4083-4089. doi:10.1021/ acs.bioconjchem. 8 b00697

Rathore, B., Sunwoo, K., Jangili, P., Kim, J., Kim, J. H., Huang, M., et al. (2019). Nanomaterial Designing Strategies Related to Cell Lysosome and Their Biomedical Applications: A Review. Biomaterials 211, 25-47. doi:10.1016/ j.biomaterials.2019.05.002
Sainsbury, F., Zeng, B., and Middelberg, A. P. (2014). Towards Designer Nanoemulsions for Precision Delivery of Therapeutics. Curr. Opin. Chem. Eng. 4, 11-17. doi:10.1016/j.coche.2013.12.007

Settembre, C., Fraldi, A., Medina, D. L., and Ballabio, A. (2013). Signals from the Lysosome: a Control centre for Cellular Clearance and Energy Metabolism. Nat. Rev. Mol. Cel Biol 14, 283-296. doi:10.1038/nrm3565

Simeone, L., Mangiapia, G., Irace, C., Di Pascale, A., Colonna, A., Ortona, O., et al. (2011). Nucleolipid Nanovectors as Molecular Carriers for Potential Applications in Drug Delivery. Mol. Biosyst. 7, 3075-3086. doi:10.1039/ c1mb05143a

Swastika, S., Chaturvedi, A., Hazari, P. P., Jha, P., Pal, S., et al. (2019). Evaluation of BBB Permeable Nucleolipid (NLDPU): A Di-C15-ketalised Palmitone Appended Uridine as Neuro-Tracer for SPECT. Int. J. Pharmaceutics 565, 269-282. doi:10.1016/j.ijpharm.2019.04.074

Usenovic, M., and Krainc, D. (2012). Lysosomal Dysfunction in Neurodegeneration. Autophagy 8, 987-988. doi:10.4161/auto.20256

Yim, W. W.-Y., and Mizushima, N. (2020). Lysosome Biology in Autophagy. Cell Discov 6, 6. doi:10.1038/s41421-020-0141-7

Zeng, J., Martin, A., Han, X., Shirihai, O. S., and Grinstaff, M. W. (2019). Biodegradable PLGA Nanoparticles Restore Lysosomal Acidity and Protect Neural PC-12 Cells against Mitochondrial Toxicity. Ind. Eng. Chem. Res. 58, 13910-13917. doi:10.1021/acs.iecr.9b02003

Zeng, J., Shirihai, O. S., and Grinstaff, M. W. (2020). Modulating Lysosomal pH: a Molecular and Nanoscale Materials Design Perspective. JoLS 2, 25-37. doi:10.36069/jols/20201204

Zhang, S., Li, J., Lykotrafitis, G., Bao, G., and Suresh, S. (2009). Size-Dependent Endocytosis of Nanoparticles. Adv. Mater. 21, 419-424. doi:10.1002/adma.200801393

Zhou, X., Wang, S., Zhu, Y., Pan, Y., Zhang, L., and Yang, Z. (2020). Overcoming the Delivery Barrier of Oligonucleotide Drugs and Enhancing Nucleoside Drug Efficiency: The Use of Nucleolipids. Med. Res. Rev. 40, 1178-1199. doi:10.1002/ med.21652

Conflict of Interest: The authors declare that the research was conducted in the absence of any commercial or financial relationships that could be construed as a potential conflict of interest.

Publisher's Note: All claims expressed in this article are solely those of the authors and do not necessarily represent those of their affiliated organizations, or those of the publisher, the editors and the reviewers. Any product that may be evaluated in this article, or claim that may be made by its manufacturer, is not guaranteed or endorsed by the publisher.

Copyright (c) 2021 Brouillard, Barthélémy, Dehay, Crauste-Manciet and Desvergnes. This is an open-access article distributed under the terms of the Creative Commons Attribution License (CC BY). The use, distribution or reproduction in other forums is permitted, provided the original author(s) and the copyright owner(s) are credited and that the original publication in this journal is cited, in accordance with accepted academic practice. No use, distribution or reproduction is permitted which does not comply with these terms. 